\title{
Functional Analysis of Fis in Aeromonas Veronii TH0426 Reveals a Key Role in the Regulation of Virulence and Adhesion
}

\section{Xintong Li}

Jilin Agricultural University

Haichao Song

Jilin Agricultural University

Jinglin Wang

Jilin Agricultural University

Dongxing Zhang

Jilin Agricultural University

Xiaofeng Shan

Jilin Agricultural University

Bintong Yang

Jilin Agricultural University

Yuanhuan Kang

Jilin Agricultural University

Aidong Qian

Jilin Agricultural University

Lei Zhang

Jilin Agricultural University

Wuwen Sun ( $\sim$ sunwuwensci@163.com )

Jilin Agricultural University

\section{Research Article}

Keywords: Aeromonas veronii, virulence, AAA+ family, pathogenicity, Fis

Posted Date: March 30th, 2021

DOI: https://doi.org/10.21203/rs.3.rs-352104/v1

License: (a) This work is licensed under a Creative Commons Attribution 4.0 International License.

Read Full License 


\section{Abstract}

Background: Aeromonas veronii is a comorbid pathogen that can infect humans, animals, and various aquatic animals. In recent years, an increasing number of cases of $A$. veronii infection have been reported, and its virulence and drug resistance have also been increasing gradually, indicating serious risks. This bacterium not only threatens public health and safety but also causes considerable economic loss in the aquaculture industry; however, little is known about its pathogenic mechanism.

Results: In this study, we first constructed the A. veronii TH0426 Fis gene deletion strain $\Delta$ Fis and the complementation strain C-Fis through homologous recombination technology. The results showed that the adhesion and invasion ability of the $\Delta$ Fis deletion strain towards Epithelioma papulosum cyprini (EPC) cells and the cytotoxicity were 3.8-fold and 1.3-fold lower, respectively, than those of the wild-type strain. The animal pathogenicity of $\Delta$ Fis was 2.9 -fold lower than that of the wild-type strain. In addition, the bacterial load of the deletion strain $\Delta$ Fis in crucian carp was significantly lower than that of the wildtype strain, and the load decreased with time. In summary, deletion of the Fis gene led to a decrease in the virulence of $A$. veronii.

Conclusions: Our research results show that the deletion of the Fis gene significantly reduces the virulence and adhesion ability of $A$. veronii TH0426. Therefore, the Fis gene plays a vital role in the pathogenesis of TH0426. This preliminary study of the function of the Fis gene in A. veronii will help researchers further understand the pathogenic mechanism of $A$. veronii.

\section{Background}

A.veronii is a gram-negative facultative anaerobic bacterium that is widely found in freshwater, seawater, silt, and soil[1, 2]. It was isolated from patients with diarrhoea and wound infection by the Centers for Disease Control and Prevention (CDC) in 1983. It is a zoonotic pathogen that can cause disease in humans, animals, and a variety of aquatic organisms[3,4]. In recent years, there have been an increasing number of cases of $A$. veronii infecting various aquatic animals, warm-blooded animals, and even humans around the world[5-10]. A. veronii can cause various diseases, such as skin rot disease, gill rot, and sepsis, and even morbidity and death in aquatic animals. Human infection can cause gastroenteritis, pneumonia, and traumatic infections, and these occurrences not only cause considerable economic loss in the breeding industry but also threaten food quality and public health[11-13]. At present, research on $A$. veronii is limited to the isolation and identification of certain diseased animals, and there is very little research on its pathogenic mechanism[14-17]. Therefore, investigation of its virulence factors will enable us to better understand its pathogenic mechanism, which will contribute to the prevention and control of the occurrence of large-scale infection by $A$. veronii.

Almost every major process in cells is carried out by macromolecular machines[18]. Protein complexes have highly coordinated moving parts, and the conformational changes of these moving parts are driven by energy. These macromolecular machines require additional equipment that plays a role in their 
assembly. This supplementary device, usually referred to as a molecular chaperone protein, can help in the non-covalent assembly of other proteins or protein complexes[19,20]. The remodelling function of molecular chaperones can make the substrate protein more proteolytic. This function serves as a quality control mechanism to eliminate faulty components that cannot be integrated correctly. Chaperones can also modulate the activity of protein complexes by mediating the degradation or availability of specific components[21, 22]. Evolution-related molecular chaperones that play a role in the assembly or regulation of molecular machines may be related to a variety of cellular activities. This is the case with members of the $\mathrm{AAA}^{+}$family, which represent ATPases involved in diverse cellular activities $[23,24]$. The $A A A^{+}$family of ATPases is present in all living organisms, and these proteins are involved in various cellular processes, including membrane fusion, proteolysis, and DNA replication[25]. Many AAA $^{+}$family proteins usually perform chaperone-like functions, such as promoting protein folding and unfolding, protein complex assembly or disassembly, and protein transport and degradation, but some other proteins play a role in replication, recombination, repair, and transcription[26, 27]. The Fis gene encodes an ATPase of the $\mathrm{AAA}^{+}$family, so this gene may affect protein folding, which is related to the pathogenicity and virulence of bacteria. However, there is no research showing the function of the Fis gene in A. veronii, so we will explore this aspect to understand the infection mechanism of $A$. veronii.

In this study, we deleted the main sequence of the Fis gene in A. veronii through homologous recombination and constructed a $\Delta$ Fis mutant strain and an overexpression strain, C-Fis. We compared and analysed the growth characteristics, haemolytic activity, biofilm formation ability, pathogenic ability, adhesion ability, and cytotoxicity of the three strains. Our findings will further clarify the pathogenic mechanism of the bacterium and provide a deeper theoretical basis. The results will allow us to reduce the harm caused by $A$. veronii to public health and lay a theoretical foundation for the development of vaccines for bacteria.

\section{Results}

\subsection{Construction and detection of $\Delta$ Fis and C-Fis}

To determine whether the $\Delta$ Fis and C-Fis strains were successfully constructed, we extracted Ribonucleic Acid (RNA) from the deletion strain $\triangle$ Fis and the wild-type strain TH0426 using reverse-transcribed Complementary Deoxyribonucleic acid (cDNA) as the template for verification with the primers $\mathrm{P}_{3-1} / \mathrm{P}_{3-2}$. The target fragment could not be amplified from the deletion strain $\Delta$ Fis, but a 1409 bp fragment was amplified from the wild-type strain, which proved that the results were consistent with expectations. The RNA of the complementation strain C-Fis was extracted for PCR verification, and a 1409 bp fragment was amplified, which was the same as the result for the wild-type strain. In contrast to the wild-type strain, $\Delta$ Fis could not express the Fis gene, while the Fis gene expression level of C-Fis was 223-fold that of the wild-type strain, indicating that $\Delta$ Fis and C-Fis were successfully constructed.

\subsection{No significant effect of $\Delta$ Fis on growth}


After culturing the deletion strain $\Delta$ Fis and the complementation strain C-Fis on LB solid medium, the colony morphology was observed and compared with that of the wild-type strain TH0426, but there was no significant difference. The three strains were all gram-negative bacteria that had short and rod-shaped cells that existed alone or in pairs. The colony shape was round, the surface was smooth, and the edges were neat. The growth rate of the three strains was determined to clarify the function of the Fis gene during the growth process. The results showed that the growth ability of the deletion strain $\Delta F i s$ was not significantly different from that of the complementation strain C-Fis and the wild-type strain TH0426 (Fig 1).

\subsection{Haemolytic activity}

Comparison of the haemolytic activity of the deletion strain $\Delta F i s$, the complementation strain C-Fis and the wild-type strain TH0426 showed that the haemolytic activity did not change significantly among the three strains, indicating that the Fis gene has no significant relationship with the haemolytic activity of the strain.

\subsection{Effect of Fis gene deletion on motility}

Previous research by this research group showed that $\mathrm{TH} 0426$ has the ability to swim. The swimming abilities of the deletion strain $\Delta$ Fis and the complementation strain C-Fis were tested. The results showed that the swimming distance of $\Delta$ Fis was $1.65 \pm 0.35 \mathrm{~cm}$, the swimming distance of C-Fis was $1.65 \pm 0.40$ $\mathrm{cm}$ and the swimming distance of TH0426 was $1.35 \pm 0.15 \mathrm{~cm}$ (Fig 2), so there was no significant difference in swimming ability among $\Delta$ Fis, C-Fis, and TH0426.

\subsection{Effect of $\Delta$ Fis gene on biofilm formation ability}

The $\mathrm{OD}_{575}$ value can reflect the amount of biofilm formed by a strain and the intensity of biofilm formation. The results show that the $\mathrm{OD}_{575}$ values of $\Delta$ Fis and C-Fis were $1.27 \pm 0.23$ and $1.23 \pm 0.38$, respectively, while the $\mathrm{OD}_{575}$ values of the wild-type strain TH0426 and negative control PBS were $1.74 \pm$ 0.59 and $0.20 \pm 0.02$ (Fig 3), respectively. This indicates that due to inactivation of the Fis gene, the biofilm formation ability of the $\Delta F i s$ deletion strain was reduced, but the difference was not significant. Therefore, the Fis gene cannot regulate the biofilm formation of $A$. veronii.

\subsection{Fis deletion reduced the virulence of TH0426}

The toxicity of the deletion strain $\Delta F i s$, the complementation strain C-Fis and the wild-type strain $A$. veronii TH0426 was tested by the cytotoxic kit. The results showed that the cell viability of EPC cells after inoculation with the deletion strain $\Delta$ Fis was 1.38 -fold that of the wild-type strain A. veronii $\mathrm{TH} 0426(\mathrm{P}<$ 
0.001) (Fig 4). Since cell viability is directly proportional to the number of viable cells, this finding indicates that the deletion strain $\Delta$ Fis was less cytotoxic than the wild-type strain A. veronii TH0426, while the complementation strain C-Fis was more cytotoxic than the deletion strain $\Delta$ Fis.

\subsection{Adhesion and invasion ability detection}

The test results for the adhesion and invasion abilities of the EPC cells showed that the bacterial adsorption rate of TH0426 was 3.8-fold that of $\Delta$ Fis (Fig 5). The adhesion and invasion abilities of the deletion strain $\Delta$ Fis were significantly weaker than those of the wild-type strain A. veronii TH0426, while the adhesion and invasion abilities of the complementation strain C-Fis were restored but not obvious. This indicates that the Fis gene has a certain influence on the adhesion and invasion abilities of $A$. veronii.

\subsection{Determination of the half-lethal dose $\left(\mathrm{LD}_{50}\right) \mathrm{n}$ zebrafish}

A zebrafish infection model was established and used to calculate the zebrafish median lethal dose to determine the change in virulence of the deleted strain $\Delta$ Fis. The $L_{50}$ value of TH0426 was $(7.60 \pm 0.32)$ $\times 10^{5} \mathrm{CFU} /$ tail, the $\mathrm{LD}_{50}$ value of the deletion strain $\Delta$ Fis was $(2.28 \pm 0.16) \times 10^{6} \mathrm{CFU} /$ tail, and the $\mathrm{LD}_{50}$ value of the complementation strain C-Fis was $(1.37 \pm 0.29) \times 10^{6} \mathrm{CFU} /$ tail. The results showed that the $\mathrm{LD}_{50}$ value of $\Delta$ Fis was 2.99 -fold higher than that of TH0426 $(\mathrm{P}<0.001)$, indicating that the virulence of $\Delta$ Fis was lower than that of the wild type (Fig 6) and that C-Fis exhibited slight virulence recovery.

\subsection{Detection of virulence gene expression}

The detection results for the four virulence genes aerolysin (aer), serine protease (ser), elastase (ahyB) and lipase (lip) in the wild-type strain, deletion strain and complementation strain are shown in Fig 7. The serine protease gene expression level in the deletion strain $\Delta$ Fis was 2.96-fold that in TH0426, and the elastase gene expression level in the deletion strain $\Delta$ Fis was 0.38 -fold that in $\mathrm{TH} 0426$.

\subsection{Bacterial load test}

The wild-type strain, deletion strain and complementation strain were used to challenge crucian carp. The results showed that the average bacterial loads in the TH0426 wild-type strain in the liver, spleen, and kidney after $24 \mathrm{~h}$ were $5.41 \times 10^{5} \mathrm{CFU} / \mathrm{g}$ and $4.63 \times 10^{5} \mathrm{CFU} / \mathrm{g}$, and $2.18 \times 10^{4} \mathrm{CFU} / \mathrm{g}$, respectively; the loads in the $\Delta$ Fis deletion strain were $1.44 \times 10^{5} \mathrm{CFU} / \mathrm{g}, 3.57 \times 10^{3} \mathrm{CFU} / \mathrm{g}$ and $4 \times 10^{3} \mathrm{CFU} / \mathrm{g}$, respectively.

Seventy-two hours after the crucian carp were challenged, the average bacterial loads in the TH0426 wildtype strain in the liver, spleen and kidney were $6.60 \times 10^{2} \mathrm{CFU} / \mathrm{g}, 1.95 \times 10^{2} \mathrm{CFU} / \mathrm{g}$, and $1.56 \times 10^{3} \mathrm{CFU} / \mathrm{g}$, 
respectively; the loads in the deletion strain $\Delta$ Fis were $85 \mathrm{CFU} / \mathrm{g}, 103 \mathrm{CFU} / \mathrm{g}$, and $295 \mathrm{CFU} / \mathrm{g}$, respectively. The experimental results showed that at $24 \mathrm{~h}$ and $72 \mathrm{~h}$, the bacterial load of $\Delta$ Fis was significantly lower than that of the wild-type strain, and the Fis gene affected the pathogenicity of TH0426.

\section{Discussion}

In recent years, the number of research reports on $A$. veronii has gradually increased, and most of the reported illnesses are relatively serious, which has aroused much attention. $A$. veronii can produce a large number of virulence factors, such as haemolysin, enterotoxin, and adhesion factors[28]. These virulence factors play a major role in aquatic animal, livestock and even human infections. $A$. veronii, a gramnegative bacterium, contains a variety of secretion systems, among which type III and type VI secretion systems are related to the virulence of most gram-negative bacteria [29, 30]. Based on careful multiplesequence alignments, Neuwald et al. [31] proposed a broader $\mathrm{AAA}^{+}$family including the classic AAA family in 1999 and later discovered that $A A A^{+}$family proteins usually perform chaperone-like functions and help in the assembly, manipulation, or disassembly of protein complexes. Teru et al. explored the structure of $A A A^{+}$family proteins and found that the central ATPase domain (called the AAA ${ }^{+}$module) of approximately 250 amino acids is structurally conserved[32]. Nahar et al.[33] found that the AAA family protein Cdc48-Ubx2 complex regulates the conversion of the outer mitochondrial membrane protein Fzo1 by regulating the ubiquitination state of the substrate. Li et al.[34] found that AAA ${ }^{+}$ATPase TER94 can interact with the baculovirus early protein LEF3 and helicase to transport and further recruit proteins related to viral replication to establish a viral replication factory. Khong et al.[35] found that loss of the AAA family ATPase p97/VCP leads to a decrease in the actin dynamics of knockdown cells, impaired cell motility, and increased RhoA protein levels, which participate in the proteasome-dependent protein degradation pathway. The Fis gene encodes an ATPase of the AAA family in the type VI secretion system, and other members of the family participate in a variety of cellular processes. Therefore, the study of the Fis gene is of great significance to further explain the pathogenic mechanism of $A$. veronii.

In this study, the biological characteristics of the A. veronii wild-type strain TH0426, deletion strain $\Delta$ Fis and complementation strain C-Fis were analysed, and it was found that after gene deletion, the growth ability of the bacteria was almost unchanged compared with that of the wild-type strain. The swimming test showed that the swimming and surging distances of $\Delta$ Fis were almost unchanged compared with those of the wild-type strain. Analysis of the Fis gene showed that it is not involved in the proliferation and motility of TH0426 cells. This result is similar to the results of Tian et al. [36] for the acid bacteriophage $\mathrm{jj} 12$, in which deletion of the type VI secretion system AAA ATPase gene $c / p B$ did not affect the proliferation and motility of the strain. However, this finding is different from that of Li Jing et al.'s[37] study of the deletion of the moxR gene related to the acid phagocytosis Aac-5AAA ATPases of watermelon, which caused the bacterium's motility and growth ability to decrease. We speculated that this trait may be affected by nucleotide metabolism. The cause remains unknown, and further research is needed. 
Bacterial biofilms are aggregate film-like substances formed by bacteria to envelop themselves to adapt to the environment. Biofilms confer drug resistance and immune tolerance to bacteria, leading to difficulties in disease treatment. The biofilm formation ability test showed that $\Delta F i s$ exhibited almost no change compared with the wild-type strain. This result is similar to the result of Tian et al.[36], who studied the xj12 strain and found that deletion of the $c / p B$ gene did not affect the biofilm formation ability of the strain. However, the finding is distinct from that of Li Jing et al.'s[37] study, in which deletion of the mox $R$ gene related to the Aac-5-mediated acid phagocytosis of watermelon resulted in enhancement of the biofilm ability of the strain. It is speculated that this trait is related to the different genes, and the Fis gene does not participate in the formation of TH0426 biofilms.

For the process of bacterial infection, recognition of the receptors on the host's surface is essential. After some biological reactions, the bacteria invade the host. Virulence factors can promote this process. In the cell adhesion and invasion tests, $\Delta$ Fis exhibited reduced cell adhesion and invasion abilities compared with TH0426. It is speculated that deletion of the Fis gene reduces the secretion of toxins and adhesion of TH0426 and reduces the ability to recognize the surface receptor of the host. This suggests that the Fis gene affects the adhesion ability of bacteria. $\triangle$ Fis exhibited reduced toxicity towards EPC cells. It was speculated that the Fis gene affects the virulence of TH0426 towards host cells, which is similar to the result of our study. When Seemuller et al.[38] studied the AAA ATPase AP460 protein of the Candidatus Phytoplasma malistrain, they found that it was related to the inhibition of virulence. The results of the zebrafish $L_{50}$ test showed that compared with that of the wild-type strain, the $\mathrm{LD}_{50}$ of $\Delta$ Fis towards zebrafish increased and the virulence decreased, which indicated that the Fis gene affected the pathogenicity of TH0426. The virulence gene expression test results showed that Fis deletion increased the expression of serine protease and reduced elastase expression in TH0426. It is speculated that the Fis gene is involved in the protein transcription process, resulting in Fis gene deletion reducing the ability of bacteria to recognize the surface receptor of the host. This resulted in reduced pathogenicity towards cells and zebrafish. This result is similar to the view of Neuwald et al.[31], who suggested that the AAA ${ }^{+}$ family Lon and Clp proteins are involved in DNA replication, recombination, and restriction in E. coli and other bacteria. The bacterial load test results showed that the bacterial load of $\Delta$ Fis was significantly lower than that of the wild-type strain, which indicated that the Fis gene affected the pathogenicity of TH0426. It is speculated that deletion of the Fis gene reduces the cell adhesion ability of TH0426 cells, resulting in a decrease in animal pathogenicity.

In summary, we successfully constructed an $A$. veronii $\Delta$ Fis-deleted strain through homologous recombination technology, verified part of the biological function of the Fis gene in $A$. veronii through preliminary exploration, and found that lack of the Fis gene affected the adhesion ability of $A$. veronii and that the virulence and pathogenicity decreased significantly. This lays the foundation for the subsequent development of $A$. veronii attenuated vaccines and the exploration of pathogenic mechanisms.

\section{Conclusions}


In summary, we successfully constructed the Fis gene deletion strain and the complementation strain for the first time and characterized the biological function of this gene through the analysis of biological characteristics. The A. veronii TH0426 strain lacking the Fis gene exhibited no significant changes in biofilm formation ability, but the bacterial cell adhesion ability, cytotoxicity and animal pathogenicity were significantly reduced. These results indicate that the Fis gene plays a crucial role in the pathogenesis of A. veronii. This study explored the function of the Fis gene in A. veronii for the first time and provided references for further exploration of the pathogenicity of $A$. veronii.

\section{Methods}

\subsection{Bacterial strains, plasmids, and growth conditions}

The wild-type strain A. veronii TH0426 used in this study was initially isolated from a farmed Pelteobagrus fulvidraco in Zhejiang Province, China. The original strains and plasmids were stored by the Preventive Veterinary Research Laboratory of Jilin Agricultural University. The bacterial strains and plasmids used in this study are listed in Table 1. All the A. veronii strains were grown in Luria-Bertani (LB) medium and Rimler-Shotts (RS) selective medium at $30^{\circ} \mathrm{C}$. The host bacterium DH5a strains and engineered E. coli strain WM3064 used in this study were grown in LB broth or plated on LB agar plates. Three vectors, namely, pEASY-Blunt Zero (pEASY), the broad-host-range expression plasmid pBBR1-MCS, and the suicide plasmid pRE112, were utilized for gene expression. When required, appropriate antibiotics were added at the following final concentrations: ampicillin (Amp, $100 \mu \mathrm{g} / \mathrm{ml}$ ) and chloramphenicol (Cm, $45 \mu \mathrm{g} / \mathrm{ml})$.

\section{Table 1}

Bacterial strains and plasmids used in this study. 
Strains

\begin{tabular}{|c|c|c|}
\hline $\begin{array}{l}\text { A. veronii } \\
\text { TH0426 }\end{array}$ & Wild-type strain, Amp ${ }^{r}$ & This study \\
\hline$\Delta$ Fis & Isogenic Fis mutant of strain $\mathrm{TH} 0426$ & This study \\
\hline C-Fis & Mutant $\Delta$ Fis complemented with intact Fis gene & This study \\
\hline $\begin{array}{l}\text { E. coli Trans1- } \\
\text { T1 }\end{array}$ & $\mathrm{F}-\phi 80\left(\right.$ lacZ) $\Delta \mathrm{M} 15 \Delta / a c X 74 \mathrm{hsdR}\left(r k^{-}, m k+\right) \Delta r e c A 1398$ endA 1 tonA & $\begin{array}{l}\text { TransGene } \\
\text { Biotech }\end{array}$ \\
\hline $\begin{array}{l}\text { E. coli } \\
\text { WM3064 }\end{array}$ & $\begin{array}{l}\text { thrB1004 pro thi rpsL hsdS lacZAM15RP4- } \\
1360 \text { (araBAD) 567DdapA1341: :[erm pir(wt)] }\end{array}$ & $\begin{array}{l}\text { Stored in our } \\
\text { lab }\end{array}$ \\
\hline $\begin{array}{l}\text { E. coli DH5a- } \\
\lambda \text { pir }\end{array}$ & $\lambda$ pir lysogen of DH5a & $\begin{array}{l}\text { Stored in our } \\
\text { lab }\end{array}$ \\
\hline
\end{tabular}

Plasmids

$\begin{array}{lll}\text { pEASY-Blunt } & \text { TA cloning vector, Amp } \\ \text { Zero } & \text { TransGene } \\ \text { Biotech }\end{array}$

pEASY-UD Fis Carrying the flanking region of the ORF for Fis TA cloning, Amp ${ }^{r} \quad$ This study

pRE112 pGP704 suicide plasmid, pir depengent, oriT, oriV, sacB, $\mathrm{Cm}^{\mathrm{r}}$

Stored in our lab

PRE112-UD pRE112 carrying the flanking region of the Fis ORF, $\mathrm{Cm}^{\mathrm{r}}$
Fis

This study

pBBR1-MCS Broad-host range vector, $\mathrm{Cm}^{\mathrm{r}}$

Stored in our lab

pBBR-Fis

pBBR carrying of $1681 \mathrm{bp}$ containing the promoter and Fis ORF,

This study $\mathrm{Cm}^{\mathrm{r}}$

\subsection{Experimental Fish}

We purchased healthy zebrafish weighing $0.5 \pm 0.03 \mathrm{~g}$ and crucian carp weighing $300 \pm 0.5 \mathrm{~g}$ from a fish farm (Changchun, Jilin, China). The crucian carp and zebrafish were fed the basal diet twice a day in the amount of $2 \%$ of their body weight for 2 weeks. Crucian carp were acclimatized in flow-through aquariums at $26 \pm 1.0^{\circ} \mathrm{C}$ and zebrafish were maintained in Racirculating Aquaculture Systems at $28 \pm$ $1.0{ }^{\circ} \mathrm{C}$, with natural photoperiod. During the whole experiment periods, the physicochemical parameters of the water were measured daily $(5.6 \pm 0.45 \mathrm{mg} / \mathrm{L}$ of dissolved oxygen, $0.12 \pm 0.01 \mathrm{mg} / \mathrm{L}$ of ammonia, $0.015 \pm 0.003 \mathrm{mg} / \mathrm{L}$ of nitrate and $7.8 \pm 0.5 \mathrm{of} \mathrm{pH}$ ). After the study, all remaining experimental animals were euthanized by bringing the concentration of cove oil in the water to $80 \mathrm{mg} / \mathrm{L}$. This study was conducted following the Jilin Agriculture University Institutional Animal Care and Use Committee 


\subsection{Construction of the $A$. veronii deletion and complementation strains}

To construct the Fis gene deletion strain, partial deletion of the Fis gene was conducted by homologous recombination. Briefly, the genome of the TH0426 strain was used as a template to amplify the flanking region of the Fis gene with the primers $\mathrm{P}_{1-1} / \mathrm{P}_{1-2}$ and $\mathrm{P}_{1-3} / \mathrm{P}_{1-4}$, and the upstream (named $\mathrm{S} 1$ ) and downstream (named S2) regions of the target gene Fis were amplified by Polymerase Chain Reaction (PCR). Using S1 and S2 as templates, the primer pair $\mathrm{P}_{1-1} / \mathrm{P}_{1-4}$ was utilized to amplify the fragment lacking the Fis gene mutation, named M Fis. The two purified flanking regions were then ligated by fusion PCR and inserted into a linear vector, pRE112, digested at the same restriction site, and the construct obtained was named pRE112-M Fis. The correctly sequenced recombinant suicide plasmid pRE112-M Fis was transformed into competent $E$. coli WM3064 cells and then conjugated into the wild-type strain $A$. veronii. A plate containing $\mathrm{Amp}$ and $\mathrm{Cm}$ was used to screen the strains for the first conjugative transfer, and then, the second homologous recombination was induced on the plate containing Amp $+10 \%$ sucrose.

The Fis gene fragment carrying the promoter region (2,252 bp) was amplified and ligated into the broadhost-range expression plasmid pBBR1-MCS of gram-negative bacteria to construct the expression plasmid Fis. Finally, Reverse Time-Polymerase Chain Reaction (RT-PCR) was used to identify the mutant $\Delta$ Fis and the complementation strain C-Fis. All primers utilized in this study were listed in Table 2.

Table 2

Primers used in study 


\begin{tabular}{|c|c|c|}
\hline Target genes & Primers & Sequence \\
\hline \multirow{2}{*}{$\begin{array}{l}\text { Fis upstream homology arm } \\
\text { sequence }\end{array}$} & $P_{1-1}(X b a I)$ & GCTCTAGACGATGCGCCGCTCGATC \\
\hline & $P_{1-2}$ & GACACTTGTGCGCGAGGGCGAATGCGA \\
\hline \multirow{2}{*}{$\begin{array}{l}\text { Fis downstream homology arm } \\
\text { sequence }\end{array}$} & $P_{1-3}$ & CGCCCTCGCGCACAAGTGTCAGAAACTGGAGGT \\
\hline & $\mathrm{P}_{1-4}(K p n \mathrm{I})$ & GGGGTACCCCTTGTCAGGGCACTGGGCC \\
\hline \multirow[t]{2}{*}{ Fis ORF and its external sequence } & $P_{2-1}$ & TTGTCGCTGGGCCCGCTTCA \\
\hline & $P_{2-2}$ & CTGGCCGATCAGCAGGATGA \\
\hline \multirow[t]{2}{*}{ Fis ORF internal sequence } & $P_{3-1}$ & TCGCAACGGGATGAACAACA \\
\hline & $P_{3-2}$ & CGCAGGCGAGCTTCAATCA \\
\hline \multirow[t]{2}{*}{ Promoter sequence } & $\begin{array}{l}\mathrm{P}_{4-1}(\mathrm{BamH} \\
\mathrm{I})\end{array}$ & CCGGATCCCTGTTTATGGGCGGC \\
\hline & $\mathrm{P}_{4-2}$ & СTTGCTCCATGGGCGTGCTCT \\
\hline \multirow[t]{2}{*}{ Fis ORF sequence } & $P_{4-3}$ & CGCCCATGGAGCAAG \\
\hline & $\begin{array}{l}\mathrm{P}_{4-4}(\text { Hind } \\
\text { III) }\end{array}$ & CGAAGCTTTCAGTTCACCTCCAGTTTC \\
\hline \multirow{2}{*}{$\begin{array}{l}\text { 16S rRNA sequence (for real-time } \\
\text { PCR) }\end{array}$} & $P_{5-1}$ & GCCACGTCTCAAGGACACAG \\
\hline & $P_{5-2}$ & TGGGGAGCAAACAGGATTAGA \\
\hline \multirow{2}{*}{$\begin{array}{l}\text { Fis ORF sequence (for real-time } \\
\text { PCR) }\end{array}$} & $P_{6-1}$ & СТCTACCACCGTCTC \\
\hline & $P_{6-2}$ & CAGTCCCTTGTCATC \\
\hline \multirow[t]{2}{*}{ pRE112 vector sequence } & $P_{7-1}$ & GCGATGAGTGGCAGGGC \\
\hline & $\mathrm{P}_{7-2}$ & TTACCGACTGCGGCCTGAGT \\
\hline \multirow[t]{2}{*}{ pBBR1-MCS vector sequence } & $P_{8-1}$ & TAAGTTGGGTAACGCCAGG \\
\hline & $P_{8-2}$ & GAGTTAGCTCACTCATTAGGC \\
\hline
\end{tabular}




\subsection{Comparison of colony morphology and determination of the growth curve}

$\triangle$ Fis, C-Fis, and A. veronii TH0426 were inoculated into LB at $1 \%$ of the culture volume and cultured at 30 ${ }^{\circ} \mathrm{C}$ for $12 \mathrm{~h}$. The concentrations of the three strains were adjusted to the same value by colony counting. The final concentration was adjusted to $1 \times 10^{6} \mathrm{CFU} / \mathrm{mL}$, and the morphology was observed by Gram staining. Then, the same amount of bacterial liquid was dropped onto a solid LB plate, and the colony morphology was observed after incubation for $35 \mathrm{~h}$ at $30^{\circ} \mathrm{C}$. The experiment was replicated three times.

$\triangle F i s, \mathrm{C}$-Fis, and $A$. veronii TH0426 at the adjusted concentrations were inoculated into liquid LB medium at $1 \%$ of the culture volume and cultured at $30{ }^{\circ} \mathrm{C}$ and $170 \mathrm{rpm}$ for $13 \mathrm{~h}$. The $\mathrm{OD}_{600}$ was measured at intervals of $1 \mathrm{~h}$ and recorded. This experiment was replicated three times.

\subsection{Determination of haemolytic activity}

To evaluate whether the haemolysin activity of Fis was affected, we performed a haemolytic activity experiment. Briefly, according to a previously described method, the cell densities of $\Delta$ Fis, C-Fis, and TH0426 were adjusted to be equal. Equal volumes of the bacterial suspensions were inoculated onto a sheep blood agar plate, and the cells were cultured at $30^{\circ} \mathrm{C}$ for $12 \mathrm{~h}$. The experiment was repeated three times.

\subsection{Motility detection}

Previous research results from this research laboratory have shown that TH0426 has swimming ability. We evaluated the swimming motility of the bacteria by measuring the colony diameter of bacteria growing on a plate containing $0.5 \%$ agar and $5 \%$ glucose. The swimming ability of $\Delta$ Fis, C-Fis, and TH0426 was tested.

\subsection{Biofilm assay}

The biofilm detection procedure was based on the method of Müsken $\mathrm{M}$ et al. [39]with appropriate modifications. The concentrations of $\Delta$ Fis, C-Fis, and TH0426 were adjusted to $1 \times 10^{6} \mathrm{CFU} / \mathrm{mL}$, and 180 $\mu \mathrm{L}$ of LB broth and $20 \mu \mathrm{L}$ of bacterial solution were added to a 96-well plate; sterile Phosphate Buffered Saline (PBS) was added to the control wells. Ten repeat wells were set up for each strain. The 96-well plate was sealed with parafilm and incubated at $28^{\circ} \mathrm{C}$ for $24 \mathrm{~h}$. After the incubation was complete, the liquid in each well was aspirated, and the well was washed twice with sterile PBS. Then, $200 \mu \mathrm{L}$ of $99 \%$ methanol was added, and the cells were fixed for $20 \mathrm{~min}$. The methanol was then aspirated, and $200 \mu \mathrm{L}$ of $0.1 \%$ crystal violet staining solution was added to each well. The solution was then aspirated, and the wells were washed three times with sterile PBS. Then, $200 \mu \mathrm{L}$ of $33 \%$ acetic acid was added to each well, 
and the plate was incubated for $5 \mathrm{~min}$. Finally, the biofilm formation ability of each strain was determined by $\mathrm{OD}_{575}$ analysis, which was repeated three times[40].

\subsection{Cytotoxicity analysis}

A cytotoxic kit was used to detect the toxicity of the deletion strain $\Delta$ Fis and the wild-type strain TH0426 to EPC cells according to the manufacturer's instructions.

\subsection{Bacterial adhesion to and invasion of EPC cells}

The adhesion and invasion abilities of $\Delta$ Fis, C-Fis, and TH0426 to EPC cells were tested[41]. EPC cells were cultured in Medium 199 (M199) medium containing 10\% foetal bovine serum and 1\% dual antibodies (penicillin and streptomycin) at $25{ }^{\circ} \mathrm{C}$ in a $5 \% \mathrm{CO}_{2}$ incubator. In brief, EPC cells were subcultured and counted, and the cell density was adjusted. And the cells were then seeded on a 24-well cell culture plate. The medium was aspirated and discarded after culturing to a monolayer, and the cells were washed twice with M199 (without antibiotics and serum). Then, M199 was used to dilute the bacterial solution at a ratio of 10:1 (bacteria: cells), and the cells were incubated for $1 \mathrm{~h}$ at $25^{\circ} \mathrm{C}$. Finally, the cells were washed three times with $\mathrm{M} 199$, and $1 \mathrm{~mL}$ of $1 \%$ Triton X-100 was added to each well and mixed well. After gradient dilution, the colonies were counted, and the adsorption rate was calculated[42].

\subsection{Challenge}

To assess the pathogenicity of the three strains, $\mathrm{LD}_{50}$ values were determined for all strains[43]. First, the deletion strain $\Delta$ Fis, the complementation strain C-Fis and the wild-type strain TH0426 were inoculated in LB culture medium and cultured for $12 \mathrm{~h}$. The bacterial colonies were counted, the concentration was calculated, and the bacterial solution was diluted 10-fold with sterile PBS. A total of 180 zebrafish were randomly divided into 3 groups with 6 gradients in each group. The bacterial solution from the previous step was used to inject the zebrafish intraperitoneally according to the corresponding gradient. The control group was injected with sterile PBS[44, 45]. After observation for one week, the number of deaths from the challenge was counted, and the $\mathrm{LD}_{50}$ of each strain towards zebrafish was calculated by the Kou method.

\subsection{Expression of virulence genes}

To analyse the cause of the change in virulence of the $\Delta$ Fis deletion strain, in this experiment, we screened 4 virulence genes for real-time quantitative PCR and detected the expression of these genes in $\Delta$ Fis and C-Fis[46]. 


\subsection{Bacterial load test}

Thirty healthy crucian carp were randomly divided into three groups, and the concentration of the bacterial solution was adjusted to $1 \times 10^{8} \mathrm{CFU} / \mathrm{mL}$ according to the above method. Crucian carp were intraperitoneally injected and inoculated, and the control group was injected with PBS. Three live fish were dissected in each group after $24 \mathrm{~h}$ and $72 \mathrm{~h}$, and the blood, liver, kidney and spleen of each fish were ground. Then, the grinding droplet plate was placed on an RS solid plate, and incubated at $28^{\circ} \mathrm{C}$ for $12 \mathrm{~h}$, followed by colony counting. The whole process was conducted under sterile conditions.

\subsection{Statistical analysis}

Statistical analysis was performed with SPSS 16.0 software and GraphPad Prism version 8.0. For all tests, statistical significance was defined as $P<0.05$. The results are expressed as the mean \pm SD of at least three independent tests.

\section{Abbreviations}

CDC: Centers for Disease Control and Prevention; LB: Luria-Bertani; RS: Rimler-Shotts; pEASY: pEASYblunt Zero; Amp: Ampicillin; Cm: Chloramphenicol; ORF: Open reading frame; OD600, OD575: Optical density; PBS: Phosphate Buffered Saline; EPC: Epithelioma papulosum cyprini; PCR: Polymerase Chain Reaction; cDNA: Complementary Deoxyribonucleic acid; RT-PCR: Reverse Time-Polymerase Chain Reaction; RNA: Ribonucleic Acid; LD $_{50}$ : Median lethal dose; Medium 199: M199.

\section{Declarations}

The authors declare no comping interests.

\section{Ethics approval and consent to participate}

The study protocol was in accordance with the ethics guidelines of Jilin Agricultural University (JLAU) and the study was approved by the review board at JLAU, Changchun, China.

\section{Consent for publication}

Not applicable.

\section{Availability of data and materials}


The datasets used and analysed during the current study are available from the corresponding author on reasonable request. All data generated or analysed during this study are included in this published article.

\section{Competing of interests}

The authors declare that they have no competing interests.

\section{Funding}

This work was supported by grants from the Key Laboratory of Healthy Freshwater Aquaculture, Ministry of Agriculture and Rural Affairs; Key Laboratory of Fish Health and Nutrition of Zhejiang Province; Zhejiang Institute of Freshwater Fisheries (Project No. ZJK202007); 13th Five-Year Science and Technology Research and Planning Project of Education Department of Jilin Province (JJKH20201294JY) and Research Startup Fund of Changchun Sci-Tech University (201913).

\section{Authors' contributions}

Study design: LXT and WJL. Study conduct, data collection and analysis: LXT. Data interpretation: SWW and SXF. Drafting of the manuscript: LXT. Revision of the manuscript content: SHC, ZDX, YBT, ZL and $\mathrm{KYH}$. Approval of the final version of manuscript: QAD and SXF. LXT take responsibility for the integrity of the data analysis and interpretation. All the authors have read and approved the final version of the manuscript.

\section{Acknowledgments}

The authors sincerely thank Dr Dongxing Zhang, Yuanhuan Kang, Lei Zhang, Bintong Yang, Wuwen Sun and Xiaofeng Shan for their assistance in the improvement of the experimental ideas and for technical assistance. We thank Haichao Song for the editing of the manuscript.

\section{References}

1. Shameena SS, Kumar K, Kumar S, Kumar S, Rathore GJA. Virulence characteristics of Aeromonas veronii biovars isolated from infected freshwater goldfish (Carassius auratus). 2019;518:734819.

2. Abbott SL, Cheung WKW, Janda JMJJoCM. The Genus Aeromonas: Biochemical Characteristics, Atypical Reactions, and Phenotypic Identification Schemes. 2003;41(6):2348-57.

3. Hickmanbrenner FW, Macdonald KL, Steigerwalt AG, Fanning GR, Farmer JJJjocm. Aeromonas veronii, a new ornithine decarboxylase-positive species that may cause diarrhea. 1987;25(5):900-6. 
4. Dallal MMS, Fard RMN, Talkhabi MK, Aghaiyan L, Salehipour ZJG. Prevalence, virulence and antimicrobial resistance patterns of Aeromonas spp. isolated from children with diarrhea. 2016;6(3):91.

5. Rahman M, Colque-Navarro P, Kuhn I, Huys G, Swings J, Mollby RJA, et al. Identification and Characterization of Pathogenic Aeromonas veronii Biovar Sobria Associated with Epizootic Ulcerative Syndrome in Fish in Bangladesh. 2002;68(2):650-5.

6. Andreia, Cruz, and, Tnia, Caetano, and, et al. Aeromonas veronii, a tributyltin (TBT)-degrading bacterium isolated from an estuarine environment, Ria de Aveiro in Portugal. 2007;64(5):639-50.

7. Dahanayake PS, Hossain S, Wickramanayake MVKS, Microbiology GJHJLiA. Prevalence of virulence and antimicrobial resistance genes in Aeromonas species isolated from marketed cockles (Tegillarca granosa) in Korea. 2020;71(1).

8. Reyes-Rodrguez NE, Salgado-Miranda C, Flores-Valle IT, Gonzlez-Gmez M, Vega-Snchez VJJoFP. Molecular Identification and Virulence Potential of the Genus Aeromonas Isolated from Wild Rainbow Trout (Oncorhynchus mykiss) in Mexico. 2019;82(10):1706-13.

9. Raj NS, Swaminathan TR, Dharmaratnam DA, Raja SA, Lal KKJA. Aeromonas veronii caused bilateral exophthalmia and mass mortality in cultured Nile tilapia, Oreochromis niloticus (L.) in India. 2019;512:734278.

10. Sanchez-Cespedes J, Figueras MJ, Aspiroz C, Aldea MJ, Toledo M, Alperi A, et al. Development of imipenem resistance in an Aeromonas veronii biovar sobria clinical isolate recovered from a patient with cholangitis. 2009;58(4):451-5.

11. Gonzalez-Serrano CJ, Santos JA, Garcia-Lopez ML, Otero AJJoAM. Virulence markers in Aeromonas hydrophila and Aeromonas veronii biovar sobria isolates from freshwater fish and from a diarrhoea case. 2010;93(3):414-9.

12. Ran C, Qin C, Xie M, Zhang J, Zhou ZJEM. Aeromonas veronii and aerolysin are important for the pathogenesis of motile aeromonad septicemia in cyprinid fish. 2018;20(9).

13. Nawaz M, Khan SA, Khan AA, Sung K, Tran Q, Kerdahi K, et al. Detection and characterization of virulence genes and integrons in Aeromonas veronii isolated from catfish. 2010;27(3):327-31.

14. Abdelhamed H, Lawrence ML, Waldbieser GJDiB. Complete genome sequence data of multidrugresistant Aeromonas veronii strain MS-18-37. 2019;23.

15. Smyrli M, Triga A, Dourala N, Varvarigos P, Pavlidis M, Quoc VH, et al. Comparative Study on A Novel Pathogen of European Seabass. Diversity of Aeromonas veronii in the Aegean Sea. 2019;7(11).

16. Hossain S, Silva BCJD, Dahanayake PS, Zoysa MD, Heo GJJAoM. Phylogenetic characteristics, virulence properties and antibiogram profile of motile Aeromonas spp. isolated from ornamental guppy ( Poecilia reticulata ). 2020;202(3):501-9.

17. Vicenta, Albarral, Ariadna, Sanglas, Montserrat, Palau, et al. Potential pathogenicity of Aeromonas hydrophila complex strains isolated from clinical, food, and environmental sources. 2016.

18. Alberts, Cell BJ. The cell as a collection protein machines: Preparing the next generation of molecular biologists. 1998;92(3):291-. 
19. Jin G, Xu C, Zhang X, Long J, Rezaeian AH, Liu C, et al. Atad3a suppresses Pink1-dependent mitophagy to maintain homeostasis of hematopoietic progenitor cells.

20. Baker TA, Bell SPJC. Polymerases and the Replisome: Machines within Machines. 1998;92(3):295305.

21. Eisenberg-Lerner A, Benyair R, Hizkiahou N, Nudel N, Merbl YJNC. Golgi organization is regulated by proteasomal degradation. 2020;11(1):409.

22. Chaney, Genes MJ, Development. Binding of transcriptional activators to sigma 54 in the presence of the transition state analog ADP-aluminum fluoride: insights into activator mechanochemical action. 2001;15(17):2282-94.

23. Beyer AJPS. Sequence analysis of the AAA protein family. 2010;6.

24. Jonathan, M., Wagner, Timothy, J., Evans, et al. Crystal structure of the N-terminal domain of EccA1ATPase from the ESX-1 secretion system ofMycobacterium tuberculosis. 2013;82(1):159-63.

25. Ye Q, Lau RK, Mathews IT, Birkholz EA, Corbett KDJMC. HORMA Domain Proteins and a Trip13-like ATPase Regulate Bacterial cGAS-like Enzymes to Mediate Bacteriophage Immunity. 2020;77(4).

26. Shen PSJNS, Biology M. Rearranging AAA+ architecture to accommodate folded substrates. 2020;27(2).

27. Dey S, Biswas M, Sen U, Dasgupta JJJoBC. Unique ATPase Site Architecture Triggers cis -Mediated Synchronized ATP Binding in Heptameric AAA + -ATPase Domain of Flagellar Regulatory Protein FlrC *. 2015;290.

28. Organization FAJSoWF, Aquaculture. The State of World Fisheries and Aquaculture: opportunities and challenges. 2014;4(78):40-1.

29. A MFA, B ES, C EH, D MKK, E AL, F MAENJF, et al. Effects of dietary Nannochloropsis oculata on growth performance, serum biochemical parameters, immune responses, and resistance against Aeromonas veronii challenge in Nile tilapia (Oreochromis niloticus) - ScienceDirect. 2020;107:277-88.

30. González-Serrano CJ, Santos JA, García-López ML, Otero AJJoAM. Virulence markers in Aeromonas hydrophila and Aeromonas veronii biovar sobria isolates from freshwater fish and from a diarrhoea case. 2002;93(3).

31. Neuwald AF, Aravind L, Spouge JL, Koonin EVJGR. AAA+: A Class of Chaperone-Like ATPases Associated with the Assembly, Operation, and Disassembly of Protein Complexes. 1999;9(1):27-43.

32. Kiyonobu, Karata, Chandra, S., Verma, Anthony, et al. Probing the mechanism of ATP hydrolysis and substrate translocation in the AAA protease FtsH by modelling and mutagenesis. 2001;39(4):890903.

33. Sabiqun N, Abhijit C, Teru O, Masatoshi EJJoB. A AAA ATPase Cdc48 with a cofactor Ubx2 facilitates ubiquitylation of a mitochondrial fusion-promoting factor Fzo1 for proteasomal degradation.

34. Li Y, Hu L, Chen T, Chang M, Wang MJJoV. Host AAA+ ATPase TER94 Plays Critical Roles in Building the Baculovirus Viral Replication Factory and Virion Morphogenesis. 2020;94(6):-. 
35. Khong ZJ, Lai SK, Koh CG, Geifman-Shochat S, Li HYJO. A novel function of AAA-ATPase p97/VCP in the regulation of cell motility. 2020;11(1).

36. Yanli, Tian, Yuqiang, Zhao, Xinrong, Wu, et al. The type VI protein secretion system contributes to biofilm formation and seed-to-seedling transmission of Acidovorax citrullion melon. 2014.

37. Li J YY, Zhao TC. Functional analysis of AAA ATPases genes ( $m$ oxR and ruvB) in Acidovorax citrulli. Acta Phytopathology. 2016;46(06):748-58.

38. Seemüller E, Zikeli K, Furch ACU, Wensing A, Jelkmann WJEJoPP. Virulence of 'Candidatus Phytoplasma mali' strains is closely linked to conserved substitutions in AAA+ ATPase AP460 and their supposed effect on enzyme function. 2017.

39. Müsken M, Di Fiore S, R?Mling U, H?Ussler SJNP. A 96-well-plate-based optical method for the quantitative and qualitative evaluation of Pseudomonas aeruginosa biofilm formation and its application to susceptibility testing. 2010;5(8):1460-9.

40. Thurnheer T, Gmür R, Guggenheim BJJoMM. Multiplex FISH analysis of a six-species bacterial biofilm. 2004;56(1):37-47.

41. Fijan N, Sulinamovic D, Bearzotti M, Muzinic D, Zwillenberg LO, Chilmonczyk S, et al. Some properties of the Epithelioma papulosum cyprini (EPC) cell line from carp Cyprinus carpio [carp pox, Herpes virus, cell culture; karyotype, rhabdoviruses, fish pathology]. 1983;134(2):207-20.

42. Winton J, Batts WF, Dekinkelin P, Leberre MF, Fijan NJJoFD. Current lineages of the epithelioma papulosum cyprini (EPC) cell line are contaminated with fathead minnow, Pimephales promelas, cells. 2010;33(8):701-4.

43. Velázquez M, Feirtag JMJIJoFM. Helicobacter pylori: characteristics, pathogenicity, detection methods and mode of transmission implicating foods and water. 1999;53(2-3):95-104.

44. Paletta ACC, Castro VS, Conte-Junior CAJCM. Shiga Toxin-Producing and Enteroaggregative Escherichia coli in Animal, Foods, and Humans: Pathogenicity Mechanisms, Detection Methods, and Epidemiology. 2020;77(4):612-20.

45. Levin REJFB. Campylobacter jejuni: A Review of its Characteristics, Pathogenicity, Ecology, Distribution, Subspecies Characterization and Molecular Methods of Detection. 2007;21(4):271-347.

46. A LZ, A MS, B NY, C XWZ, E SHAR, A KJ, et al. Nucleoside Diphosphate Kinases (ndk ) reveals a key role in adhesion and virulence of Aeromonas veronii. 149.

\section{Figures}




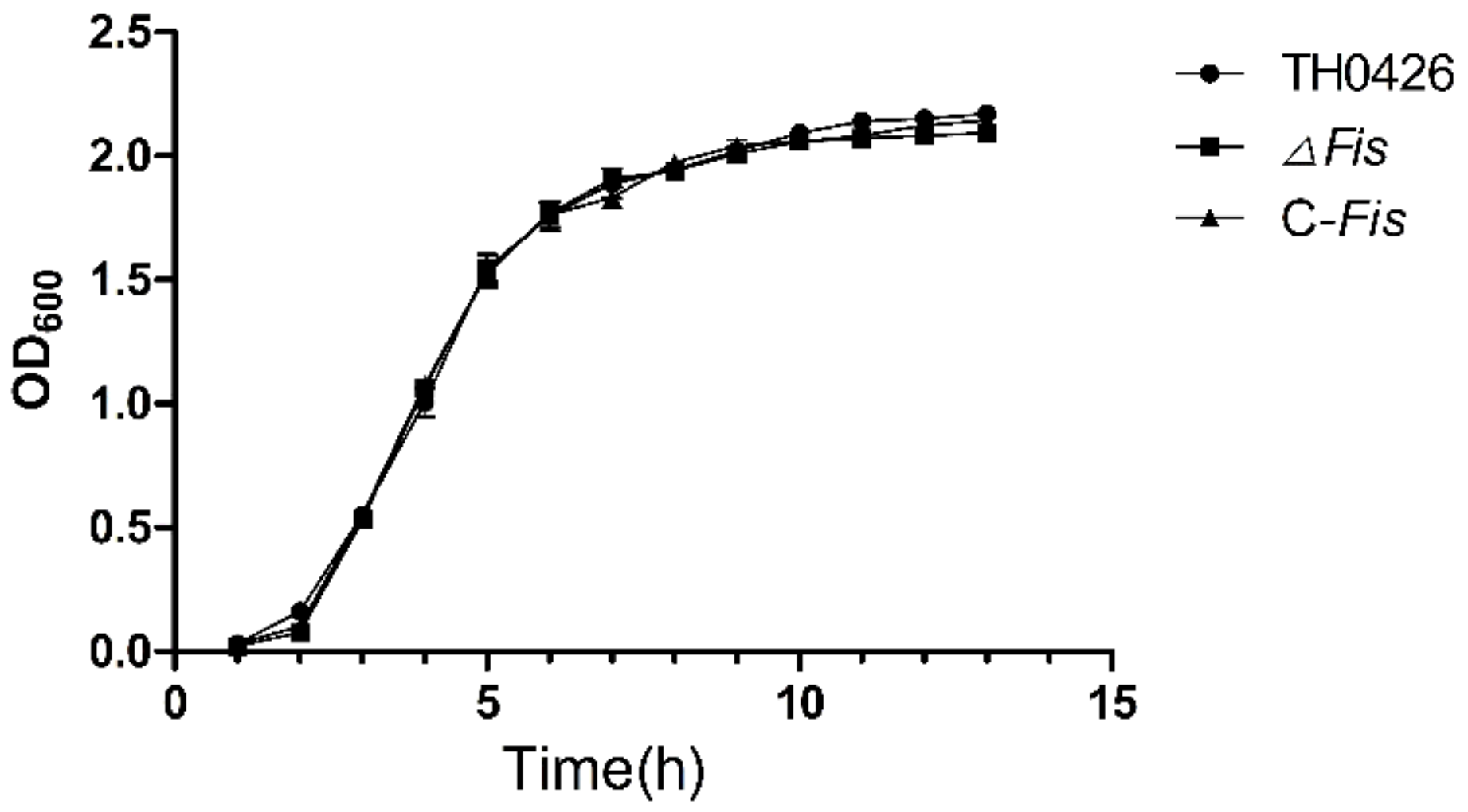

Figure 1

Growth curves of wild-type TH0426, $\Delta$ Fis, and C-Fis. 


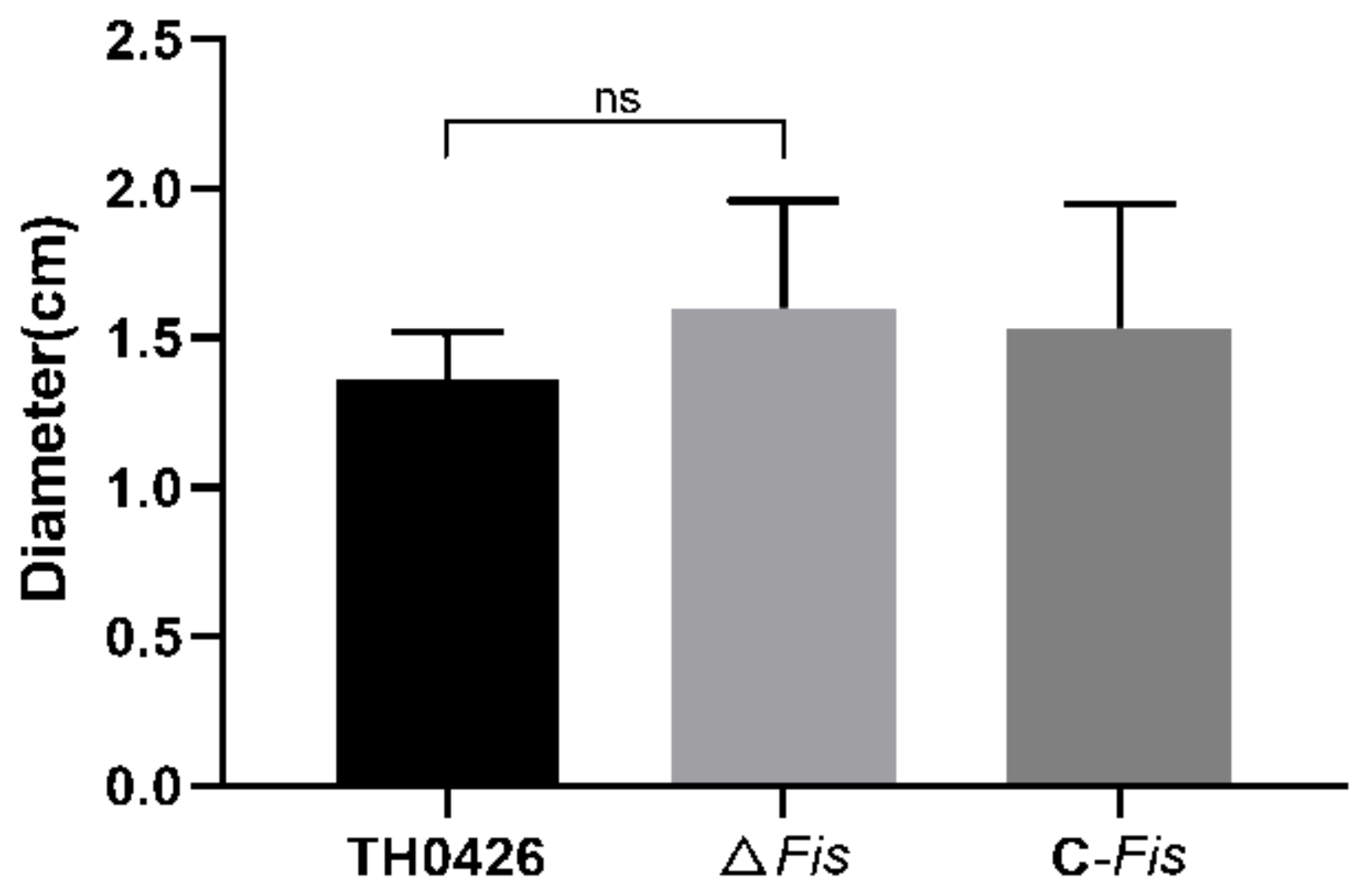

Figure 2

Swimming ability of wild-type TH0426, $\Delta$ Fis, and C-Fis. (n.s. indicates no significant difference). 


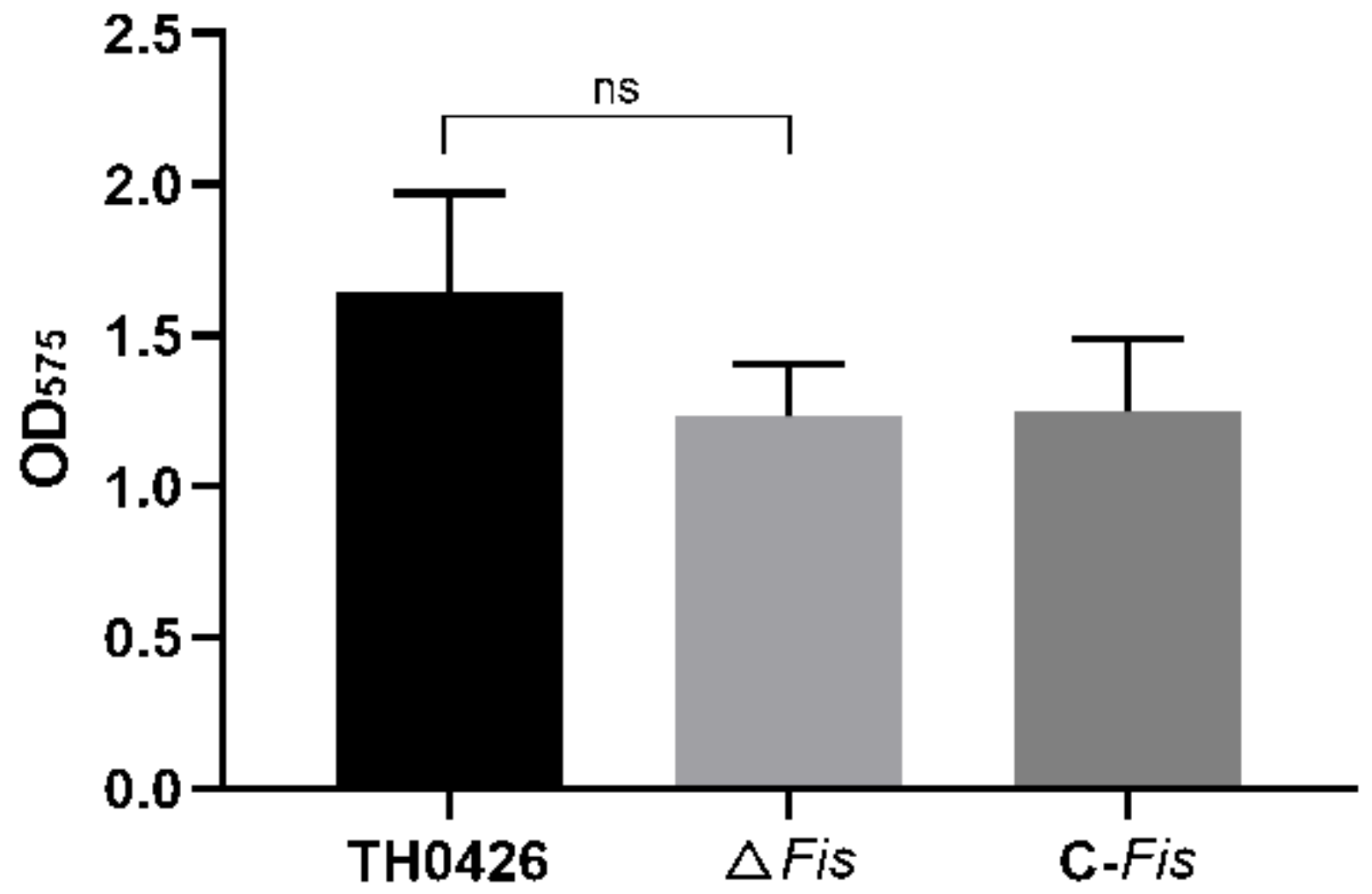

Figure 3

Biofilm formation ability of wild-type TH0426, $\Delta$ Fis, and C-Fis. The amount of biofilm formation is represented by the OD575 value. (n.s. indicates no significant difference). 


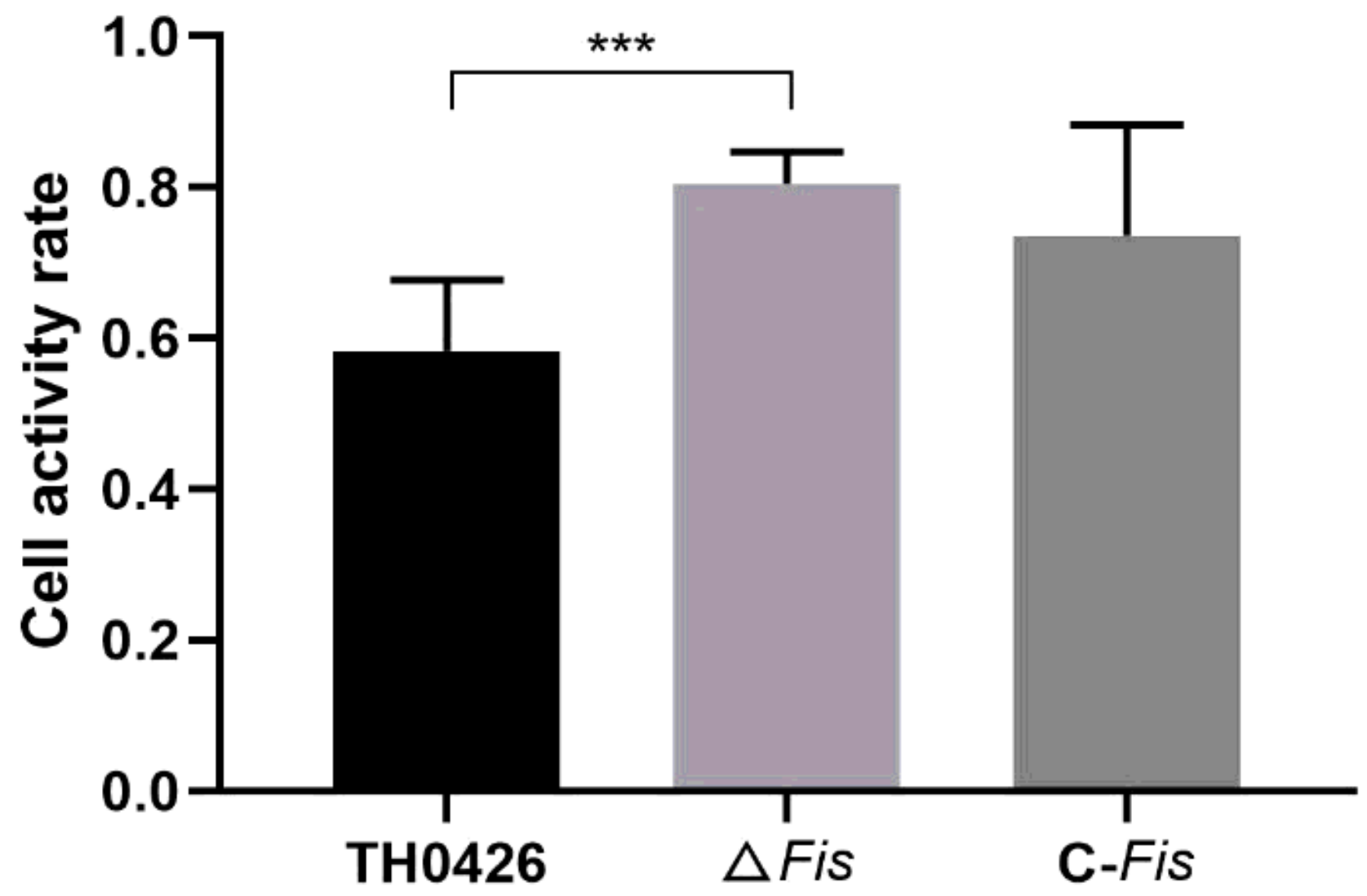

Figure 4

Cytotoxicity test of wild-type TH0426, $\Delta$ Fis, and C-Fis. Since cell viability is directly proportional to the number of surviving cells, it is inversely proportional to cytotoxicity ( $\star \star \star$ indicates $\mathrm{P}<0.001$ ). 


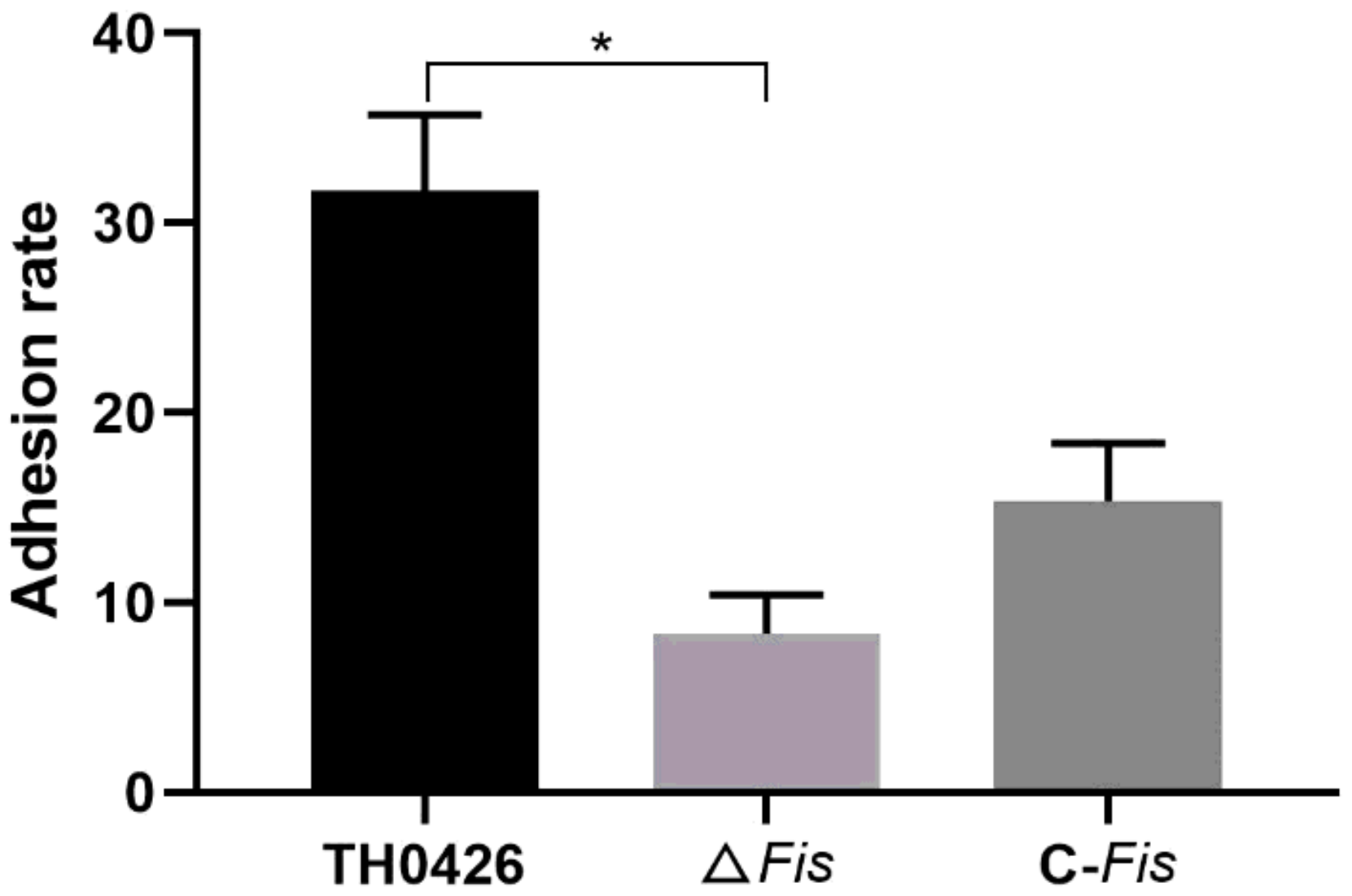

Figure 5

Detection of the adhesion and invasion abilities of wild-type TH0426, $\Delta$ Fis, and C-Fis towards EPC cells. The data are expressed as the adherence rate ( $*$ indicates $P<0.05)$. 


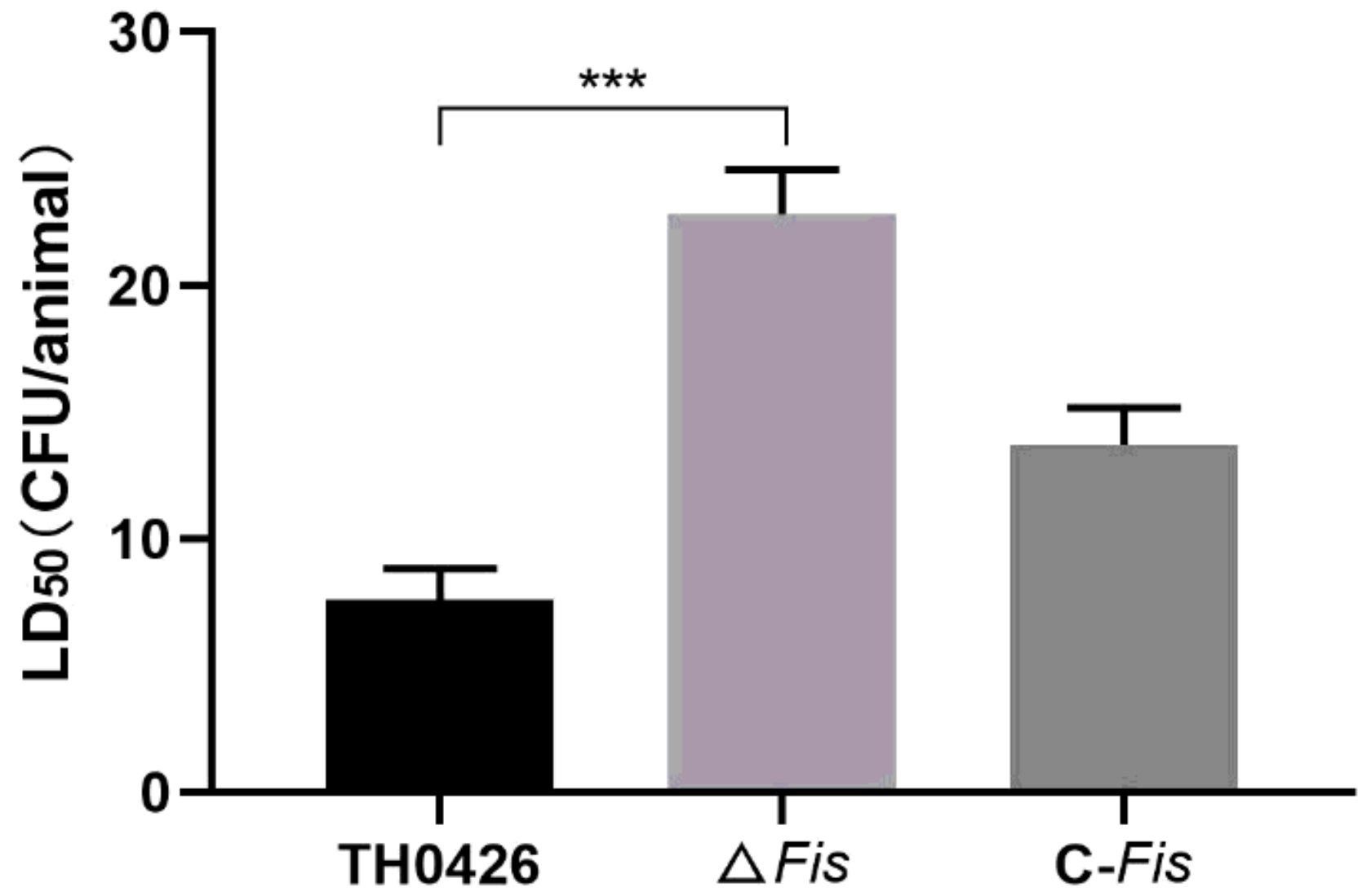

Figure 6

Survival rate of adult zebrafish challenged with wild-type TH0426, $\Delta$ Fis, and C-Fis. The LD50 value represents the median lethal dose in zebrafish ( $* \star \star$ indicates $P<0.001)$. 


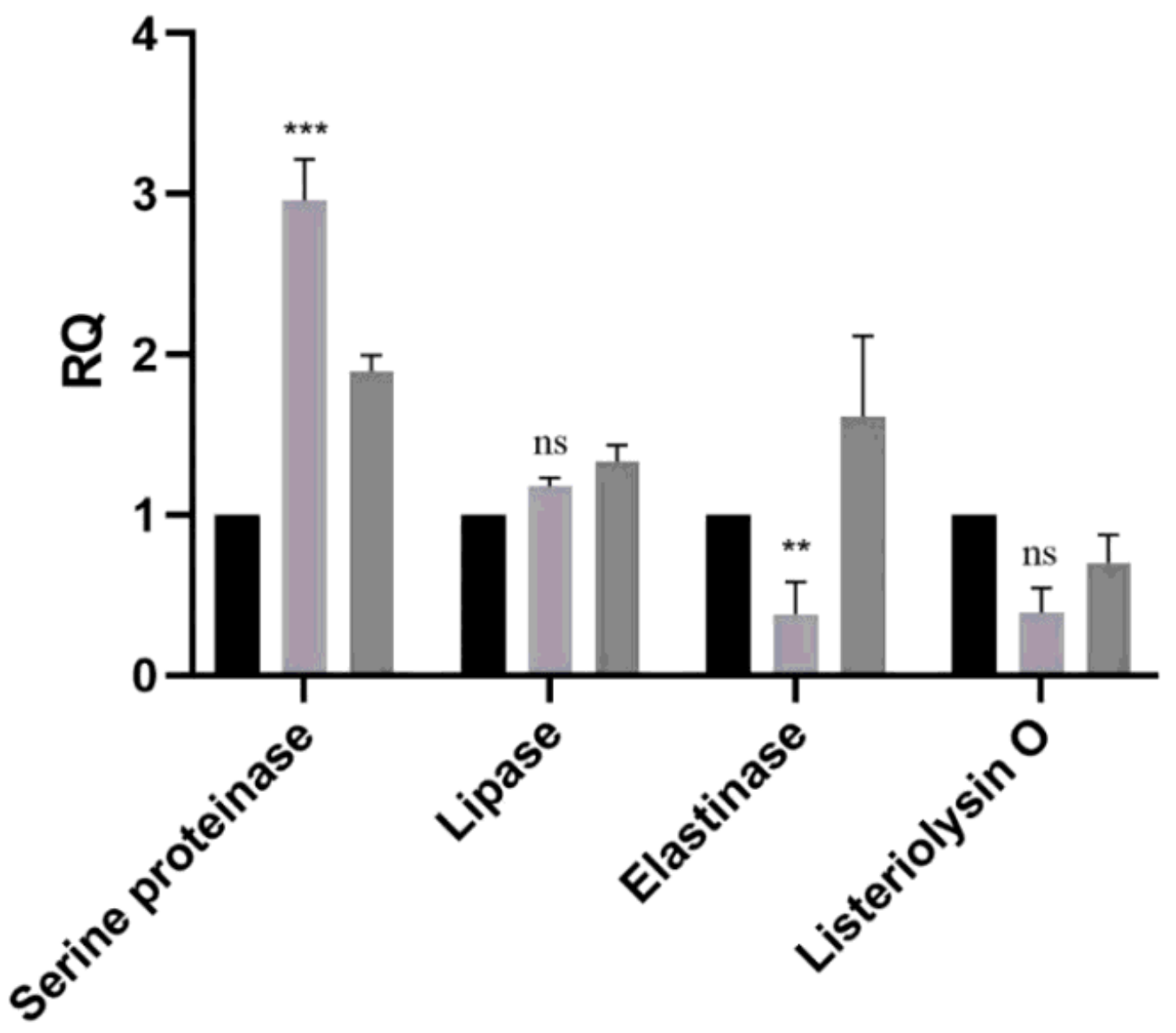

- TH0426

$\triangle$ Fis

C-Fis

Figure 7

Expression of virulence genes in wild-type TH0426, $\Delta$ Fis, and C-Fis. 